\title{
Rim and Exocytosis: Rab3a-Binding and Secretion-Enhancing Domains Are Separate and Function Independently
}

\author{
LEI SUN, MARY A. BITTNER, AND RONALD W. HOLZ \\ Department of Pharmacology, University of Michigan Medical School, \\ Ann Arbor, Michigan, USA
}

\begin{abstract}
Rim1 has been identified in brain by its ability to bind Rab3a-GTP and has been postulated to be a Rab3a effector protein. Like Rabphilin3, another putative Rab3a effector protein, Rim1 modulates secretion and contains a zinc-finger and two $\mathrm{C} 2$ domains. We have investigated the structural basis for the ability of Rim1 to bind Rab3a-GTP and to stimulate exocytosis in chromaffin cells.
\end{abstract}

KeYwORDs: Rim1; Rab3a; Rabphilin3; secretion; exocytosis

Rab proteins are Ras-like GTPases involved in mediating membrane trafficking in eukaryotic cells. ${ }^{1-3}$ The Rab3 subfamily is associated with secretory granules and vesicles. Rim1 was identified in brain by its ability to bind Rab3a-GTP and has been postulated to be a Rab3a effector protein. ${ }^{4,5}$ Like Rabphilin3, ${ }^{6-8}$ another putative Rab3a effector protein, Rim 1 modulates secretion and contains a zinc-finger and two C2 domains (FIGS. 1A and 1B). We have investigated the structural basis for the ability of Rim 1 to bind Rab3a-GTP and to stimulate exocytosis in chromaffin cells. ${ }^{9}$

\section{MINIMAL DOMAIN REQUIRED TO ENHANCE SECRETION}

Both full-length and N-terminal Rim1 enhance secretion by $40-50 \%$ in both intact and permeabilized cells. To determine the minimal region of Rim 1 necessary for the enhancement of secretion, $\mathrm{N}$ - and $\mathrm{C}$-terminal deletion mutants were constructed from Rim(1-399). The enhancement of secretion was maintained when 50 or fewer amino acids were deleted from the N-terminal (FIG. 1C). Further deletions caused loss of enhancing activity, with Rim(71-399) having no effect on secretion. $\mathrm{C}$-terminal deletions revealed that activity was maintained in constructs as short as Rim(1-190) (FIG. 1D). This construct contains the four pairs of cysteines that

Address for correspondence: Mary A. Bittner, Department of Pharmacology, University of Michigan Medical School, 2301 MSRB III, Ann Arbor, MI 48109-0632. Voice: 734-647-3127; fax: 734-763-4450

mbittner@umich.edu

Ann. N.Y. Acad. Sci. 971: 244-247 (2002). () 2002 New York Academy of Sciences. 
A. Riml

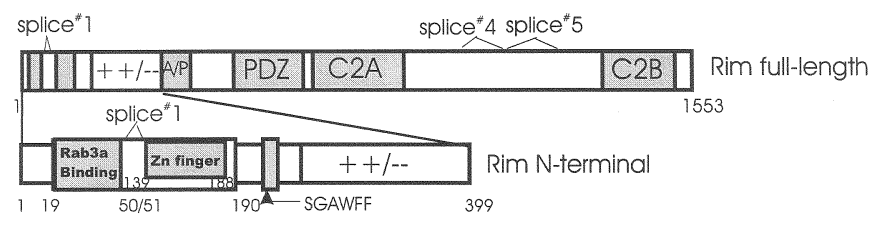

\section{B. Rabphilin3}



C. N-terminal Deletions of Rim(1-399)

D. C-terminal Deletions of Rim(1-399)
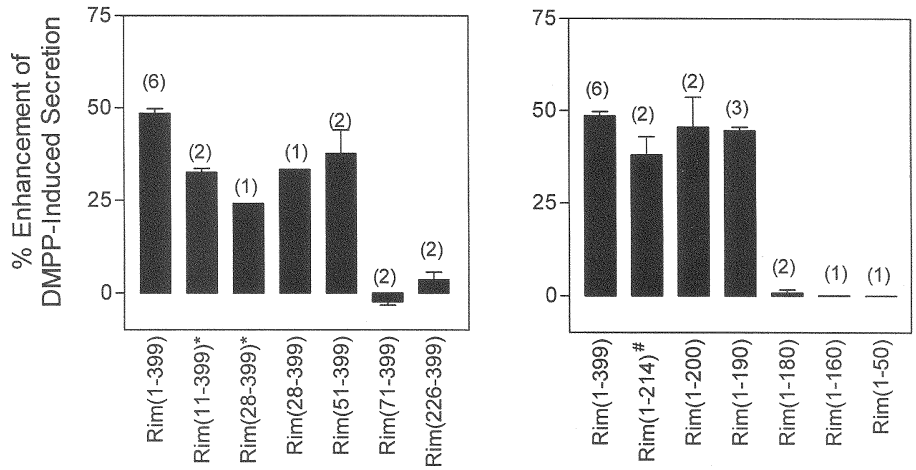

FIGURE 1. Schematic diagram of Rim1 and Rabphilin3 and effects on secretion of Rim constructs. (A) Rim1: Full-length Rim1 contains numerous domains including a zincfinger domain, a highly charged region (++/--), an alanine and proline-rich domain (A/P), a PDZ domain, and two C2 domains. There are also three splice sites (numbered according to Ref. 5). The expanded view of N-terminal Rim 1 shows the Rab3a-binding domain (amino acids 19-50) and the minimal domain that enhances secretion (amino acids 51-190) as demonstrated in this study. (B) Rabphilin3: Amino acids are numbered from the bovine brain sequence. $^{7}(\mathbf{C} \& \mathbf{D})$ Chromaffin cells were cotransfected with plasmids encoding human growth hormone (hGH) and either pCMV.neo or Rim constructs. Four to five days later, cells were incubated in physiological salt solution for $2 \mathrm{~min} \pm$ the nicotinic agonist dimethylphenylpiperazinium (DMPP, $20 \mu \mathrm{M}$ ). Data are presented as the percent enhancement of DMPPinduced hGH secretion relative to hGH secretion from cells transfected with control plasmid pCMV.neo. The numbers of experiments performed are indicated in parentheses above the error bars. Constructs labeled with an asterisk $\left(^{*}\right)$ are without the deletion in splice site \#1 (see Ref. 4). Constructs labeled with "\#” have residues 83-105 deleted in splice site \#1. All other Rim constructs have residues 56-105 deleted in splice site \#1. Adapted from Sun et al. ${ }^{9}$ 
constitute a zinc-finger domain, but does not contain the SGAWFF motif (residues 198-203) that in Rabphilin3 plays a critical role in binding to Rab3a-GTP. ${ }^{10}$

\section{IDENTIFICATION OF THE RAB3A-BINDING DOMAIN IN RIM1}

N-terminal deletion mutants of Rim1 were expressed as GST-Rim1 fusion proteins, bound to glutathione-Sepharose beads, and incubated with lysates from human embryonic kidney 293 cells transiently expressing HA-Rab3a and either GTP $\gamma \mathrm{S}$ or GDP. Rim 1 constructs lacking the N-terminal 19 amino acids still specifically bound Rab3a-GTP, whereas further deletion (28 amino acids) completely prevented Rab3a binding. Removal of the SGAWFF motif [Rim(1-190)] or removal of all the pairs of conserved cysteines $[\operatorname{Rim}(1-50)]$ did not prevent specific binding to Rab3a, indicating that the zinc-finger motif is not needed for binding to Rab3a. No binding was detected for two shorter constructs, Rim(1-39) and Rim(1-28).

We conclude that the abilities of Rim 1 to enhance secretion and to bind Rab3aGTP reside on distinct and relatively small domains that act independently. A sequence of $\sim 30$ amino acids immediately $\mathrm{N}$-terminal of the zinc-finger constitutes the minimal Rab3a-GTP-binding domain. This short sequence is not found in Rabphilin3 and is entirely different from the zinc-finger and flanking regions of Rabphilin3 that bind Rab3a-GTP. The zinc-finger domain in Rim1 is unnecessary for Rab3a-GTP binding, but alone enhances secretion. The interaction with Rab3a-GTP, although not necessary for the enhancement of secretion, is likely to serve another function, perhaps allowing the proper transport or localization of Rim1 in the neuron.

While both Rabphilin3 and Rim1 enhance secretion, the respective domains involved are significantly different. Previous studies have shown that both C2 domains as well as the zinc-finger are required for the enhancement of secretion by Rabphilin3. ${ }^{7,8}$ Rabphilin3 constructs lacking the $\mathrm{C} 2$ domains inhibit secretion rather than enhance it. In contrast, enhancement of secretion by Rim 1 requires only the intact zinc-finger. These differences are likely to reflect different mechanisms underlying the enhancements of secretion by these two proteins.

The ability of transiently expressed constructs of Rim1 to enhance secretion in permeabilized cells indicates that the enhancing effects are a direct effect of the proteins on the $\mathrm{Ca}^{2+}$-dependent secretory pathway and not on $\mathrm{Ca}^{2+}$ entry. Addition of the recombinant zinc-finger domain to permeabilized chromaffin cells also enhances secretion. Analysis of the enhancement of secretion in permeabilized cells indicated that N-terminal Rim 1 does not alter the sensitivity of secretion to $\mathrm{Ca}^{2+}$, but instead increases the rate of ATP-dependent priming of secretion. The results suggest that the Rim zinc-finger domain stimulates exocytosis at a late step in the secretory pathway through a mechanism that does not require Rab3a.

\section{ACKNOWLEDGMENTS}

This work was supported by grants from the NIH to R.W. Holz (Nos. RO1 DK50177 and RO1 DK27959). 


\section{REFERENCES}

1. Novick, P. \& P. BRennwald. 1993. Friends and family: the role of the Rab GTPases in vesicular traffic. Cell 75: 597-601.

2. BajJalieh, S.M. \& R.H. Scheller. 1995. The biochemistry of neurotransmitter secretion. J. Biol. Chem. 270: 1971-1974.

3. Novick, P. \& M. Zerial. 1997. The diversity of Rab proteins in vesicle transport. Curr. Opin. Cell Biol. 9: 496-504.

4. WANG, Y., M. Oкамото, F. Schmitz, et al. 1997. Rim is a putative rab3 effector in regulating synaptic-vesicle fusion. Nature 388: 593-598.

5. WANG, Y., S. Sugita \& T.C. Sudhof. 2000. The RIM/NIM family of neuronal C2 domain proteins: interactions with Rab3 and a new class of Src homology 3 domain proteins. J. Biol. Chem. 275: 20033-20044.

6. Shirataki, H., K. Kaibuchi, T. SaKoda, et al. 1993. Rabphilin-3A, a putative target protein for smg p25A/rab3A p25 small GTP-binding protein related to synaptotagmin. Mol. Cell. Biol. 13: 2061-2068.

7. Chung, S-H., Y.T. Akai \& R.W. Holz. 1995. Evidence that the rab3a-binding protein, rabphilin3a, enhances regulated secretion: studies in adrenal chromaffin cells. J. Biol. Chem. 270: 16714-16718.

8. Chung, S-H., P. Stabila, I.G. Macara \& R.W. Holz. 1997. Importance of the Rab3aGTP binding domain for the intracellular stability and function of Rabphilin3a in secretion. J. Neurochem. 69: 164-173.

9. Sun, L., M.A. BitTneR \& R.W. Holz. 2001. Rab3a binding and secretion-enhancing domains in Rim1 are separate and unique. J. Biol. Chem. 276: 12911-12917.

10. Ostermeier, C. \& A.T. BRUnGer. 1999. Structural basis of Rab effector specificity: crystal structure of the small $\mathrm{G}$ protein Rab3a complexed with the effector domain of Rabphilin-3a. Cell 96: 363-374. 